\title{
REVIEWS
}

\section{A Comparison of IHC and FISH Cytogenetic Methods in the Evaluation of HER2 Status in Breast Cancer}

Department of Pathomorphology and Oncological Cytology, Wroclaw Medical University, Poland

A - research concept and design; $\mathbf{B}$ - collection and/or assembly of data; $\mathbf{C}$ - data analysis and interpretation;

$\mathbf{D}$ - writing the article; $\mathbf{E}$ - critical revision of the article; $\mathbf{F}$ - final approval of article

\begin{abstract}
The HER2 gene is responsible for the formation of the HER2 receptor on the surface of epithelial cells. Increased numbers of this receptor are associated with a worse prognosis in cancer. Increased numbers of copies of the HER2 gene occur in about $20-30 \%$ of breast cancer patients, so determining HER2 receptor levels is important in the current diagnosis and treatment of breast cancer. One diagnostic technique is the immunohistochemical (IHC) method, which permits indirect measurement of overexpression of HER2 receptors, based on subjective determination of the intensity of the color reaction. Another technique is the use of fluorescent in situ hybridization (FISH), which permits the exact number of copies of the HER2 gene to be specified. Based on the results of FISH tests, patients can be qualified for treatment with antibodies that partially block HER2 receptors. This treatment causes inhibition of tumor growth signals. Determining the HER2 status in breast cancer with the FISH method allows the further progress of the disease to be predicted, the right treatment to be chosen and the response to the treatment to be foreseen. Because of the widespread use of the FISH and IHC methods, comparing the advantages and disadvantages of these two methods seems to be relevant (Adv Clin Exp Med 2015, 24, 5, 899-904).
\end{abstract}

Key words: breast cancer, immunohistochemistry, HER-2/neu, fluorescence in situ hybridization.

Due to amplification of the HER2 gene in $20-30 \%$ of patients with breast cancer [1], determination of HER2 status in those patients has a great importance in clinical practice [2]. HER2 gene amplification correlates with negative predictors [3] and is associated with a shorter survival time, a higher percentage of recurrences of cancer and a lower response to chemotherapy and hormone therapy [4]. Jana et al. [5] state that overexpression of the HER2 protein is associated with a large tumor size and advanced tumor stage.

\section{HER2 and GRB7: Genes from the 17q11-12 Amplicon with Predictive Value in Breast Cancer}

Overexpression of the HER2 receptor is the result of the amplification of the gene located on chromosome 17 (17q11-12) [6]. There are, however, cases of patients with breast cancer in whom overexpression of HER2 receptor occurs without amplification of the HER2 gene [7-9]. The opposite situation - when amplification of the HER2 gene does not cause overexpression of the HER2 protein - also occurs. One of the mechanisms causing this inconsistency is incomplete amplification of a smaller region on chromosome 17q11-12, on which the GRB7 gene is located. Amplification of the HER2 gene without overexpression of the HER2 protein is clinically important, because it prevents patients with breast cancer from benefitting from targeted HER2 therapy [10]. The GRB7 gene may amplify and cause GRB7 protein overexpression [11]. The GRB7 gene plays an important role in the growth and migration of cancer. The GRB7 protein can interact with the HER2 protein (among other things) [12]. Amplification of the $G R B 7$ gene is associated with increased transcriptional activation and, irrespective of HER2 status, may have a high predictive value in the treatment of breast cancer [13]. 


\section{Cytogenetic Methods}

There are many methods for determining HER2 receptor overexpression, such as polymerase chain reaction (PCR), immunohistochemistry (IHC), fluorescent in situ hybridization (FISH), silver enhanced in situ hybridization (SISH) or chromogenic in situ hybridization (CISH). IHC and FISH are the two main methods in clinical practice for assessing HER2 gene status [14].

\section{Fluorescent In Situ Hybridization}

Due to its sensitivity and specificity, FISH is regarded as the "gold standard". A decade ago, fluorescent microscopes equipped with the appropriate filters were quite expensive and not every laboratory could afford this equipment [14], but nowadays fluorescent microscopes are not unobtainable. McManus et al. [15] find FISH an objective and reliable method for measuring HER2 amplification. This method is used not only in the diagnosis of breast and stomach tumors [16], but also to monitor the response to treatment for these tumors [17].

\section{Immunohistochemistry}

The immunohistochemical method is cheaper, convenient to carry out and storage of the specimens is easier [18]. However, it is a semi-quantitative method [19], because it is based on a subjective determination of the intensity of the color reaction. There is still a debate about which method is the preferred one for determining HER2 gene status.

\section{A Comparison of the FISH and IHC Methods}

Because of the widespread use of FISH and IHC methods, comparing the advantages and disadvantages of these two methods seems to be relevant. In a study comparing the FISH and IHC methods, Gould et al. [17] reported that FISH is increasingly considered to be the most accurate and predictive test for determining HER2 amplification and the response to the treatment of breast cancer. The results of several studies [20,21] suggest that FISH has higher accuracy than IHC and is a better prognostic indicator in the case of highrisk breast cancers. In the study by Goud et al. [17], 90 breast cancer tissue samples were used to analyze the FISH and IHC methods. The authors suggest that HER2 status should be evaluated using FISH in all cases with IHC $2+$. IHC $3+$ results can be analyzed with FISH in order to exclude chromosome 17 polysomy, which can be misinterpreted as HER2 overexpression in when using the IHC method. The authors state that it is necessary to determine the cut-off values for HER2 amplification results with FISH against HER2 overexpression results with IHC, to make it possible to compare and calibrate the two methods [17]. The concordance rate of results obtained by the FISH and IHC methods is controversial [9]. Generally, comparative studies of these two methods show a high concordance of results. Overexpression of the HER2 protein may be found without amplification of the HER2 gene, or HER2 gene amplification can occur without overexpression of the HER2 protein [21]. Tubbs et al. [22] documented that there is a large discordance rate between FISH and IHC for all four IHC scores $(0,1+, 2+, 3+)$, and they suggest using only the FISH method in diagnostics. Similar studies were carried out by Singhai et al. [9], who analyzed 50 cases of breast cancer. The concordance of results was $82 \%$ of all cases of breast cancers. The authors concluded that the immunohistochemical method can be used primarily as a screening method to determine HER2 status. They also concluded that FISH can be an additional, complementary method to detect false negative IHC results, especially those with a high degree of malignancy. A study by Dolan and Snover [23] showed that the concordance rate between FISH and IHC results is $27.1 \%$. Lan et al. [24] documented amplification of the HER2 gene with the FISH method in only 96 out of 221 cases of breast cancer, and found that the concordance rate of the two methods is $44.4 \%$. Also, on the basis of their study, Kuo et al. [25] reported a high degree of discordance between the FISH and IHC methods. According to other authors [26], FISH and IHC correlate well with each other when IHC results at level $2+$ are in concordance with the results of FISH. Wand et al. [27] obtained a high rate of concordance: $98 \%$. IHC negative and IHC $1+$ results showed no gene amplification with the FISH method. IHC $3+$ results showed gene amplification with FISH, while results of IHC $2+$ showed a large discordance with the results of the FISH method [27]. The results of a study by Panjwani et al. [28] show that there is no statistically significant relationship between HER2 status and tumor size. A positive correlation occurs between the stage of the cancer and HER2 status, which is confirmed by the literature [29]. The research carried out by Panjwani et al. shows that $64.5 \%$ of tumors with a high degree of malignancy (grade 3 tumors) are correlated with HER2 gene amplification. 
Most studies (including the one by Panjwani et al.) generally present high concordance rate between IHC $3+$ results and FISH results showing HER2 gene amplification, and between negative IHC results and FISH results with no HER2 gene amplification. The discordance between IHC and FISH methods is related mainly to IHC $2+$ results. This discordance is an indicator of undetermined HER2 status [30]. Several studies show an approximately $20 \%$ discordance rate in HER2 status results between IHC and FISH [31]. In a study by Apple et al., the discordance rate is only 5\% [32]. The possible reasons for discordant results are differences in pre-analytic factors such as binding time, or differences in laboratory processes and variances between interobservers in the evaluation of HER2 receptor status.

Another factor leading to differences between FISH and IHC results is intratumoral heterogeneity, which is a result of using core needle biopsy to take samples [32]. Rossi et al. state that tumors with IHC 2+ and FISH negative results (with no HER2 gene amplification), which are known as HER2 negative, have a worse prognosis than tumors with no or poor expression of HER2 (IHC 0 or $1+)$. A HER2 negative result is determined on the basis of the diagnostic algorithm used to qualify patients for treatment with the anti-HER2 antibody [33].

HER2 is used as a biomarker in targeted immunotherapy with trastuzumab [35], a recombined humanized monoclonal antibody used with high clinical effectiveness in patients with amplification of the HER2 gene or overexpression of the HER2 protein [36]. Many clinical trials show that FISH has a higher predictive value than IHC for response to treatment with transtuzumab $[21,35]$. On the basis of the results of FISH tests, patients can be qualified for treatment with antibodies partially blocking HER2 receptors, which inhibit tumor growth signals. However, many laboratories use IHC as the first method of choice [10].

Trastuzumab binds with the extracellular domain of HER2 protein and blocks the proliferation of HER2 gene-amplified cancer cells. It is also capable of inducing cellular toxicity against tumor cells [36]. In patients with HER2 protein overexpression, chemotherapy with trastuzumab slows the progression of the disease, leads to a higher rate of positive response to treatment and a significant reduction in mortality in comparison to chemotherapy without this drug [37]. Trastuzumab treatment is only recommended in cases where FISH results show amplification of the HER2 gene or IHC results scored 3+ [9].

\section{Other Methods Used in HER2 Diagnostics}

A relatively new method for measuring HER2 gene amplification is quantitative real-time polymerase chain reaction (PCR PCR). It is characterized by potentially high sensitivity, specificity, reliability and low cost. High sensitivity means that even nanograms of low quality DNA can be detected and quantified [38]. RT PCR was used to determine HER2 gene amplification by Chariyalertsak et al. [2]. They consider that the development of this method makes it possible to carry out more a precise quantitative analysis of gene amplification. The method is simple and quick to perform; it can be automated; and it can potentially be used as a routine test in breast cancer screening. An additional advantage of this method is that it doesn't require a specialist to interpret the results. RT PCR is viable competition for FISH [2].

Another method is immunohistochemiluminescence. It is similar to immunohistochemistry and uses chemiluminescence produced by electromagnetic radiation as the result of chemical reaction. Its intensity depends on the concentration of chemiluminescent reagent in the reaction [39]. This method has many advantages, such as high sensitivity, the stability of the reagents, and simplicity in practice. Additionally, the products are not degradable under the influence of light [40].

\section{Summary}

Overexpression of the HER2 protein may be found without the amplification of the HER2 gene, and HER2 gene amplification can occur without overexpression of the HER2 protein. Amplification of the HER2 gene without overexpression of the HER2 protein is clinically important, because patients with this type of breast cancer will not benefit from targeted HER2 therapy. The GRB7 gene is located with the HER2 gene on chromosome 17q11-12. Amplification of the GRB7 gene is associated with increased transcriptional activation and, irrespective of HER2, may have high predictive value in the treatment of breast cancer.

The immunohistochemical method can be used primarily as a screening method, allowing HER2 status to be determined. The concordance rate differs from study to study, but research results generally present a high concordance rate between IHC $3+$ results and FISH results showing HER2 gene amplification, and between negative IHC results and FISH results with no HER2 gene amplification. The discordance between IHC 
and FISH methods is related mainly to IHC $2+$ results. This discordance is an indicator of undetermined HER2 status, and because of that, HER2 status should be evaluated using FISH in all cases with IHC $2+$.
Many clinical trials show that FISH has a higher predictive value for response to treatment with trastuzumab than IHC. Trastuzumab treatment is only recommended in cases where FISH results show amplification of the HER2 gene or where IHC results indicate overexpression scored $3+$.

\section{References}

[1] Slamon DJ, Godolphin W, Jones LA: Studies of the HER-2/neu proto-oncogene in human breast and ovarian cancer. Science 1989, 244, 707-712.

[2] Chariyalertsak S, Purisa W, Vinyuvat S: HER-2/neu amplification determined by real-time quantitative PCR and its awith clinical outcome of breast cancer in Thailand. Asian Pacific J Cancer Prev 2011, 12, 1703-1706.

[3] Révillion F, Bonneterre J, Peyrat JP: ERBB2 oncogene in human breast cancer and its clinical significance. Eur J Cancer 1998, 34, 791-808.

[4] Carr JA, Havstad S, Zarbo RJ: The association of HER-2/neu amplification with breast cancer recurrence. Arch Surg 2000, 135, 1469-1474.

[5] Jana D, Mandal S, Mukhopadhyay M, Mitra D, Mukhopadhyay SK, Sarkar DK: Prognostic significance of HER2/neu and survival of breast cancer patients attending a specialized breast clinic in Kolkata, Eastern India. Asian Pacific J Cancer Prev 2012, 13, 3851-3855.

[6] Ross JS, Fletcher JA, Linette GP: The Her-2/neu gene and protein in breast cancer 2003: biomarker and target of therapy. Oncologist 2003, 8, 307-325.

[7] Hoang MP, Sahin AA, Ordonez NG, Sneige N: HER-2/neu gene amplification compared with HER-2/neu protein cand interobserver reproducibility in invasive breast carcinoma. Am J Clin Pathol 2000, 113, 852-859.

[8] Hammock L, Lewis M, Phillips C, Cohen C: Strong HER-2/neu protein overexpression by immunohistochemistry often does not predict oncogene amplification by fluorescence in situ hybridization. Hum Pathol 2003, 34, 1043-1047.

[9] Singhai R, Patil VW, Patil AV: Immunohistochemical (IHC) HER2/neu and fluorescent in situ hybridization (FISH) gene amplification of breast cancer in Indian women. Asian Pacific J Cancer Prev 2011, 12, 179-183.

[10] Luoh S, Ramsey B, Newell AH, Troxell M, Hu Z, Chin K, Spellman P, Olson S, Keenan E: HER-2 gene amplification in human breast cancer without concurent HER-2 over-expression. Springer Plus 2013, 2, 1-10.

[11] Kao J, Pollack JR: RNA interference-based functional dissection of the 17q12 amplicon in breast cancer reveals contribution of coamplified genes. Gene Chromosome Canc 2006, 45, 761-769.

[12] Shen TL, Guan JL: Grb7 in intracellular signaling and its role in cel regulation. Front Biosci 2004, 9, 192-200.

[13] Ramsey B, Bai T, Hanlon Newell A: GRB7 protein over-expression and clinical outcome in breast cancer. Breast Cancer Res Treat 2011, 127, 659-669.

[14] Sáez A, Andreu FJ, Seguí MA: HER-2/neu gene amplification by chromogenic in situ hybridization (CISH) compared with fluorescence in situ hybridization (FISH) in breast cancer-A study of two hundred cases. Breast 2006, 15, 519-527.

[15] McManus DT, Patterson AH, Maxwell P: Fluorescence in situ hybridisation detection of erbB2 amplification in breast cancer fine needle aspirates. Mol Pathol 1999, 52, 75-77.

[16] Jeziorski KG: Rak żołądka - leczenie ukierunkowane molekularnie. Onkol Prak Klin 2011, 7, 5, 258-263.

[17] Gould KI, Dayakar S, Vijayalaxmi K, Babu SJ, Vijay ARP: Evaluation of HER2/neu status in breast cancer specimens using immunohistochemistry (IHC) and fluorescence in situ hybridization (FISH) assay. Indian J Med Res $2012,135,312-317$.

[18] Reed W, Hannisdal E, Boehler PJ: The prognostic value of p53 and c-erb B-2 immunostaining is overrated for patients with lymph node negative breast carcinoma: a multivariate analysis of prognostic factors in 613 patients with a follow-up of 14-30 years. Cancer 2000, 88, 804-813.

[19] Melo Rego MJB, Cordeiro MF, Lima Bezerra Cavalcanti C, Carvalho Junior LB, Beltrao EIC: Immunohistochemiluminescence detection: A quantitative tool in breast cancer HER-2 status evaluation. Disease Markers 2013, 34, 373-377.

[20] Beatty BG, Bryant R, Wang W, Ashikaga T, Gibson PC, Leiman G, Weaver DL: HER2/neu detection in fineneedle aspirates of breast cancer: Fluorescence in situ hybridization and immunohistochemical analysis. Am J Clin Pathol 2004, 122, 246-255.

[21] Pauletti G, Dandekar S, Rong H: Assessment of methods for tissue-based detection of the HER-2/neu alteration in human breast cancer: a direct comparison of fluorescence in situ hybridization and immunohistochemistry. J Clin Oncol 2000, 18, 3651-3664.

[22] Tubbs RR, Pettay JD, Roche PC: Discrepancies clinical laboratory testing of eligibility for trastuzumab therapy: apparent immunohistochemical false positives do not get the message. J Clin Oncol 2001, 19, 2714-2721.

[23] Dolan M, Snover D: Comparison of immunohistochemical and fluorescence in situ hybridization assessment of HER-2/neu status in routine practice. Am J Clin Pathol 2005, 123, 766-770. 
[24] Lan C, Liu JM, Liu TW: erb-b2 amplification by fluorescence in situ hybridization in breast cancer specimens read as 2+ in immunohistochemical analysis. Am J Clin Pathol 2005, 124, 97-102.

[25] Kuo SJ, Wang BB, Chang CS: Comparison of immunohistochemical and fluorescence in situ hybridization assessment for HER-2/neu status in Taiwanese breast cancer patients. Taiwan J Obstet Gynecol, 2007, 46, 146-151.

[26] Kakar S, Puangsuvan N, Stevens JM: HER-2/neu assessment in breast cancer by immunohistochemistry and fluorescence in situ hybridization: comparison of results and correlation with survival. Mol Diagn 2000, 5, $199-207$.

[27] Goud KI, Dayakar S, Vijayalaxmi K, Babu SJ, Vijay ARP: Evaluation of HER2/neu status in breast cancer specimens using imunohistochemistry (IHC) and fluorescence in situ hybridization (FISH) assay. Indian J Med Res 2012, 135, 312-317.

[28] Panjwani P, Epari S., Karpate A, Shirsat H, Rajsekharan P, Basak R, Shet T, Chinoy R, Chacko R, Gursale S, Baraskar N, Gupta S, Hawaldar R, Deasi S: Assessment of HER-2/neu status in breast cancer using fluorescence in situ hybridization and immunohistochemistry: Experience of a tertiary cancer referral centre in India. Indian J Med Res 2010, 132, 287-294.

[29] Prati R, Apple SK, He J, Gornbein JA, Chang HR: Histopathologic characteristics predicting HER-2/neu amplification in breast cancer. Breast J 2005, 11, 433-439.

[30] Tsuda H, Akiyama F, Terasaki H, Hasegawa T, Kurosumi M, Shimadzu M: Detection of HER-2/neu (c-erbB-2) DNA amplification in primary breast carcinoma: interobserver reproducibility and correlation with immunohistochemical HER-2 overexpression. Cancer 2001, 92, 2965-2974.

[31] Steven S: Fluorescence in situ hybridization versus immunohistochemistry: importance of clinical outcome. J Clin Oncol 1999, 17, 3690-3692.

[32] Apple SK, Lowe AC, Rao PN, Shintaku IP, Moatamed NA: Comparison of fluorescent in situ hybridization HER-2/ /neu results on core needel biopsy and excisional biopsy in primary breast cancer. Modern Pathology 2009, 22, 1151-1159.

[33] Rossi V, Sorotto I, Maggiorotto F, Berchialla P, Kubatzki F, Tomasi N, Redana S, Martinello R, Valabrega G, Aglietta M, Ponzone R, Montemurro F: Moderate immunohistochemical expression of HER-2 (2+) without HER-2 gene amplification is a negative prognostic factor in early breast cancer. The Oncologist 2012, 17, 1418-1425.

[34] Lee S, Jung W, Hong S, Koo JS: Evaluation of intratumoral HER-2 heterogeneity by fluorescence in situ hybridization in invasive breast cancer: A single institution study. J Korean Med Sci 2011, 26, 1001-1006.

[35] Dybdal N, Leiberman G, Anderson S: Determination of HER-2/neu gene amplification by fluorescence in situ hybridization and concordance with the clinical trials immunohistochemical assay in women with metastatic breast cancer evaluated for treatment with trastuzumab. Breast Cancer Res Treat 2005, 93, 3-11.

[36] Belengeanu A, Muresan A, Stoicanescu D, Lazar E: Amplification of HER-2 gene in breast cancer: immunohistochemical and FISH assessment. Rom J Morphol Embriol 2010, 51, 321-326.

[37] Slamon DJ, Leyland-Jones B, Shak S: Use of chemotherapy plus a monoclonal antibody against for metastatic breast cancer that overexpresses HER2. N Engl J Med 2001, 344, 783-792.

[38] Chariyalertsak S, Purisa W, Vinyuvat S: HER-2/neu amplification determined by real-time quantitative PCR and its awith clinical outcome of breast cancer in Thailand. Asian Pacific J Cancer Prev 2011, 12, 1703-1706.

[39] Cao FA, Li Z, Kai H, Lu J: Chemiluminescence platforms in immunoassay and DNA analyses. Analytical Sciences 2009, 25, 587-597.

[40] Melo Rego MJB, Cordeiro MF, Lima Bezerra Cavalcanti C, Carvalho Junior LB, Beltrao EIC: Immunohistochemiluminescence detection: A quantitative tool in breast cancer HER-2 status evaluation. Dis Markers 2013, 34, 373-377.

\section{Address for correspondence:}

Marta Wesoła

Department of Pathomorphology and Oncological Cytology

Wroclaw Medical University

Borowska 213

50-556 Wrocław

Poland

E-mail: marta-wesola3@wp.pl

Conflict of interest: None declared

Received: 13.04.2014

Revised: 30.05.2014

Accepted: 27.06.2014 